\begin{tabular}{|c|c|c|}
\hline \multirow{2}{*}{$\begin{array}{l}\text { BENTHAM OPEN } \\
\text { CrossMark }\end{array}$} & $\begin{array}{c}\text { The Open Conference Proceedings } \\
\text { Journal }\end{array}$ & $\begin{array}{l}\text { T } \\
\text { c }\end{array}$ \\
\hline & $\begin{array}{l}\text { Content list available at: www.benthamopen.com/TOPROCJ/ } \\
\text { DOI: } 10.2174 / 2210289201607020029\end{array}$ & \\
\hline
\end{tabular}

\title{
Biodeterioration of Stone Monuments a Worldwide Issue
}

\author{
Piero Tiano* \\ Institute for the Conservation and the Valorization of Cultural Heritage, National Research Council, Firenze, Italy
}

\begin{abstract}
The biodegradation is a general action strictly linked in the presence of active organisms, and this is not only unavoidable but it represents a fundamental process of the Biosphere. When this process is acting on "valuable » objects, is named as Biodeterioration. The consequences surely produce a worse condition, and this process is particularly unfavourable when the object belongs to the Cultural Heritage field. Climatic factors (temperature, humidity, rain, sun exposure, and air pollutants) can establish good conditions for the development of several organisms on the surfaces, inducing first of all aesthetic damages (vegetative structures, coloured patches or patinas and crusts). Different approaches have been adopted to isolate, identify and quantify such wide group of organisms, and several methodologies and products have been used to eliminate and prevent such biological settlements. However, this field needs to subdue the sector of the qualification and to emphasise the quantification of such phenomenon. Furthermore, we have to consider this as one factor in a more general theory of Biogeomorphogenesis. A model describing the concept of stone durability, involving the Biodeterioration process, is proposed. The data of the selected parameters coming from different dominions could be integrated and elaborated in a new relational database MDDM (Management of Dynamic Durability Model). The exact knowledge of the resistance of a monumental object is crucial for a suitable schedule maintenance. Taking into consideration that the process can never be stopped but only slowed down to a minimum with balanced prevention and intervention actions.
\end{abstract}

Keywords: Biodeterioration, Biogeomorphogenesis, Conceptual model, Stone durability.

\section{PROBLEMATIC}

The biodeterioration of monumental heritage is a worldwide phenomenon. The most severe effects are found in tropical areas where the climate is extremely favourable to the growth of higher plants that can cover and destroy even big artistic monuments. The process is mainly due to centennial years of lack of maintenance, as smaller plants must be eradicated as soon as they grow. In our countries, such kind of degradation is very uncommon and limited to monuments abandoned since several years or part of them with difficulty of access. Most investigation in this field emphasised the study of microorganisms that produce stained patches or coloured crusts on the surface of stones. These microorganisms play a key role in many biogeochemical processes and can adapt themselves to extremely various environments. Modern conservation strategies underline the need to know and understand the structure and function of complex microbial communities that cause biodeterioration of materials that constitute our cultural heritage. Until recently, the detection and identification of microorganisms inhabiting cultural objects were based only on classical cultural methodologies derived from soil microbiology. These are very simple and provide information only on organisms capable of growth under artificial laboratory conditions. However, in order to carry out proper conservation actions, it is necessary to know the complete composition of microbial communities and their activity, as well explained in the review recently published [1]. Researcher's abilities to elucidate the biogeophysical and biogeochemical mechanisms of complex biodeterioration processes occurring at monumental sites have been greatly revolutionized by the use of molecular, physical and highly sophisticated so called high throughput next generation sequencing techniques. Application of these techniques in studying architectural monuments and artworks is not just limited to predict the prevalence of microbial diversity and identifying the mechanism of biodeterioration caused by inhabiting

\footnotetext{
* Address correspondence to this author at the Institute for the Conservation and the Valorization of Cultural Heritage, National Research Council, Firenze, Italy; Tel: +390555225414; Fax: +390555225403; Email: p.tiano@icvbc.cnr.it
} 
microorganisms. It also provides indepth molecular, biogeophysical and biogeochemical basis of how microorganisms respond to different environmental conditions to accelerate the process of biodeterioration. Offering in turn opportunities to develop preventive and remedial intervention to control undesirable growth and survival of microorganisms on monuments [2, 3].

This aspect represents a step forward, but the widening of the number of "strains types" that can be present on a stone surface, is necessary but not sufficient. It can be misleading for the knowledge of the effective biodeterioration action on the sampled surface. In fact, with such new techniques the DNA or RNA evidenced could be due to merely contaminants deposed on the surface or not to active biodeterioration mechanism (dead cells).

To overcome this drawback and to understand the real impact of these microorganisms on the conservation of stone monuments it is necessary, by one side, to investigate some biological markers that represent an effective viable presence with active metabolism, by another side to assess the spatial and active population in a biofilm. To the former, the presence of the ATP $[4,5]$ and the possible use of an artificial nose to detect volatile organic compounds due to the fungal metabolic activity could be employed [6]. For the latter, the study using a Confocal Laser Scanning Microscopy, with a double staining, allows to know the time spatial distribution of microorganisms and their extracellular compounds on a stone surface [7, 8]. The transportable Lidar diagnostic technique can be instead used for an early detection of photosynthetic patines [9] while the use of portable PAM device allows the control of the vitality of photosynthetic organisms [10].

The cause/effect principle should be verified to attribute a detrimental consequence to the action of a single microorganism or a biocoenosis. A possible connection for the formation of sulphate crusts and nitrate salts in stone monuments was attempted in the past for the presence of sulphur and nitrogen cycles bacteria [11, 12]. The relation cause/effect has hardly been demonstrated. Although, for some black spots their origin has been attested to the growth of black meristematic fungi, while green patines to the dwelling of cyanobacteria and green algae biocoenosis [13, 14]. The origin of some red stains on marble monuments due to heterotrophic bacteria was clearly demonstrated [15]. Even if some authors attribute this red colour to the presence of lead resistance bacteria [16] but without to close the circle. Indubitable is the attribution of a decay action to the lichenic presence [17], even if in some articles, these particular organisms are considered in some way protecting the beneath stone surface [18]. However, closing the circle rarely occurs in the conservation field. This is partly due to the distinctiveness of the "patient" and partly to difficult to isolate and cultivate the microbial agent and recreate the "illness". The Biodeterioration problematic has been deeply investigated and extensively reviewed [19 - 22].

\section{INTERVENTION}

Once investigated, classified and isolated, the active biological presence, the second step is to implement measures to stop and prevent this type of alteration. The most frequent interventions are based on the use of chemical formulates with biocide action [23]. The removal of the microbial community from any given surface is an intervention that must be carefully evaluated. Biocidal treatments may have negative effects on the artefacts [24]. The removal of the microbial community may give rise to a new succession of microorganisms, which may be more damaging than the old populations. The inhibition of specific groups of microorganisms may favour the growth of others [25].

Actions against microbial growth can be divided into four major categories: A - indirect control by altering environmental conditions; $\mathrm{B}$ - mechanical removal and eradication; C - chemicals (biocides); D - physical methods. Biocides often exhibit detrimental effects on the stone, for example, discoloration, oxidation/reduction of stone minerals, and salt formation, with subsequent crystallization upon drying, leading to exfoliation [22]. The ecotoxicity of commercial biocides does not allow use in outdoor environments and many countries have prohibited the use of some of the previously most common (and effective) biocides. Furthermore, nitrogen containing biocides may serve as nutrients for surviving or newly attaching microorganisms [21]. Where possible, microbial growth should be prevented by altering growth supporting conditions, such as introduction of a drainage system, a shelter or temporary coverage [26]. Physical methods such as UV light have been rarely applied on cultural heritage objects, due to their low penetration depth and negative influence on pigments. However, a recent preliminary study on the removal of lichens by means of a high intensity pulsed xenon flash lamp gave encouraging results [27]. Analogous intervention has been made using the microwaves to control black MCF and to kill the more sensitive algal component of a lichenic thallus [28]. More recently also laser technique has been experimented for the elimination of the biological patina [29]. A distinction needs to be made between cleaning that is designed to remove only surface soiling deposits (e.g. brushing, low pressure water washing, and low pressure blasting) and biological patines removal. An efficient treatment should 
kill damaging organisms and prevent their regrowth for an acceptable length of time while causing no damage to the substrate or deposition of chemical residues in the stone [30]. Possible treatments should be tested on a small scale, but preferentially on the affected monument itself to determine their real effectiveness against microorganism colonizing different microhabitats. A recolonization by lichens after restoration was observed, in spite of the fact that the lichen communities had been completely removed by biocides, and resins had been applied as consolidants and/or waterrepellents. Besides the usual factors favouring biological colonization, the products applied and the methodology used can affect the recolonization rate [31]. However, mixtures of consolidants or water repellents with biocides can surely increase the effective prevention of biological growth [32]. Even if, in order to understand the limitations of a coating in terms of protection and/or consolidation, it is essential to assess the impact of these products may have on further biocolonization [33].

\section{BIOGEOMORPHOGENESIS}

The biodeterioration phenomenon cannot be studied as a single process but should be considered inside the more general theory of biogeomorphogenesis, as proposed for the first time by Krumbein, in which physical/mechanical and chemical attack may influence the localization and extension of biologically induced stone damage [34, 35]. The term biocorrosion is applied when the biological activity produces deposit by chemical or mechanical means (bioerosion) leading to a volumetric loss of material from the intact stone (Fig. 1).

The biocorrosion leads to modification of the stone surface and increase in the porosity. Furthermore, alterations occurring as a function of chemical and mechanical processes are producing, such as salt crystallisation and dissolution. This process may have a considerable impact on surface roughness as area available for subsequent weathering, erosion and colonisation [36]. In fact, the deterioration of a stone material, whatever the cause, must be evaluated in the frame of its durability, a concept present in dimensional stones and monumental conservation fields. It involves how we can measure it and the challenges for its modelling. Stone deterioration is by definition dynamic, as it involves the changes in stone properties over time. Similarly, stone conservation can be defined as 'the process of handling change'. Predicted climate changes in Europe and elsewhere are likely to influence biofilms growing on stonework surfaces, with some areas expected to undergo more biodeterioration.

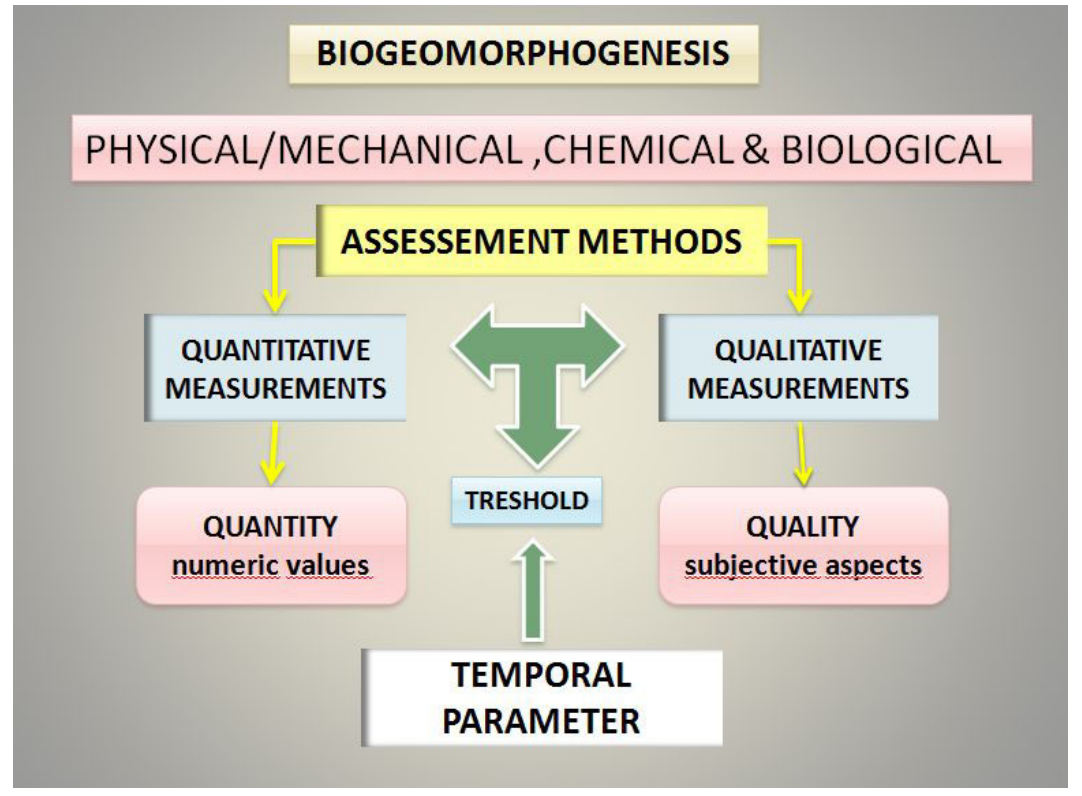

Fig. (1). Stone durability concept in the frame of biogeomorphogenesis.

Deterioration occurs when force(s) overcomes resistance(s), leading to breakdown and/or chemical change: the sum of forces represented by the relevant environmental conditions affecting the stone object, where the sum of resistances is, in effect, the durability. To measure durability we check environmental conditions and monitor the deterioration caused. Chemical and physical forces rarely act alone, and water often plays a stimulating role. The goal of preventive stone conservation is to reduce the rate of deterioration, through reducing the aggressive forces (modifying the local environmental factors) and/or increasing the resistance of those forces (applying consolidants or other treatments) [37]. 
In such vision, the stone biodeterioration can be conceptualised as a series of causes acting upon materials varying their ability to resist those causes. Measuring the causes and resistances involved in the deterioration is, in theory, relatively simple, but in reality extremely complex. We do not usually have from one side the more appropriate parameter and the right techniques to quantify its evolution in time. From another side we have to move outside the laboratory test, where the behaviour of a single parameter can be clearly evaluated in reliable manner [38] but not in realistic environment. Under field conditions, the relationships between causes and effects (resistance) are often characterized by non linear and dynamic behaviour including the presence of thresholds (Fig. 2). At present there is no test to characterize the durability of stone in relation with the richness of biodeteriorative processes [39].

Non linear systems are those in which outputs do not change proportionally to a change in inputs. One of the main problems is the difficulty of providing meaningful quantifications of inputs and, especially outputs. Taking into account that the outputs can evidence themselves in different territories and at different scales (from micro to macro). The system is clearly multicomponent (involving a range of interlinked chemical, physical, and biological processes) [37].

The lack of reliable data sets on inputs and outputs makes it difficult to interpret the system behaviour in any detailed way. Several examples indicate the presence of nonlinear, and sometimes chaotic behaviour in stone decay systems. Identification of nonlinear behaviour in stone decay systems should help interpret, model, and manage such systems in order to avoid the potential dangers of applying linear damage functions. If the variability can be explained by initial weaknesses or microclimate variations, then prediction of the trends of decay over time can be made relatively easily. If, however, chaotic conditions apply, then decay "hotspots" will occur spontaneously and the probabilistic prediction would be more appropriate [37].

There are different causes of nonlinearity, and many sources may be interrelated and operating together, and some are hard to categorize. However, it is worth attempting to identify and separate sources of nonlinearity, as they might provide the key to understand the ongoing process on and thus aid our attempts to predict and manage the conservation issues [40]. The more important are:

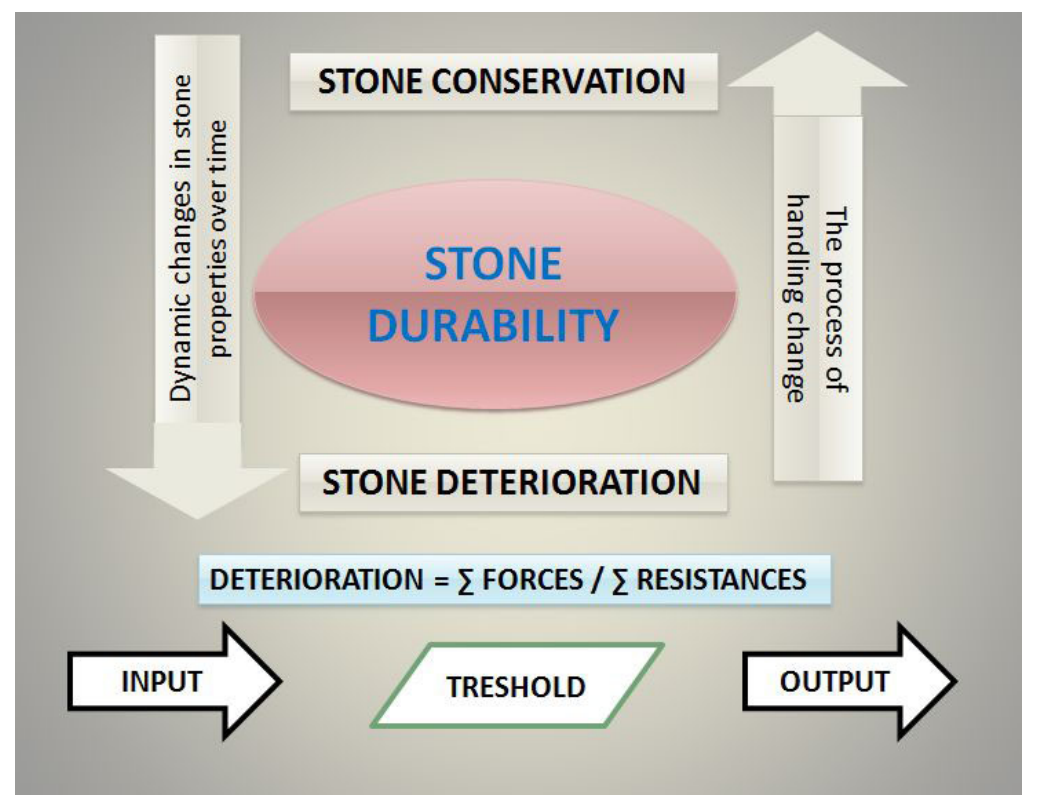

Fig. (2). From biodeterioration to stone durability.

- Threshold - inputs will lead to one type of outcome below a threshold and another type of outcome above that threshold. Thresholds thus, by definition, indicate nonlinearity.

- Saturation and depletion - may be a good way of conceptualizing the time dependent interaction.

- Storage effect - relate to situations in which the addition or removal of stored components affects input/output relationships - may be considered as the "incubation time".

- Self-reinforcing - positive feedback occurs where internal changes within a system enhances the outputs, beyond any simple relationship with inputs. Microorganism colonization may operate in a similar way, as initial biofilms produce substances that then encourage further colonization. 
- Competitive interaction - we might usefully conceptualize a competition between bioweathering and bioprotection by the lichen. A slight change in environmental conditions or indeed death of the lichen through natural aging may induce a shift to bioweathering over bioprotection [41].

- Synergism - between processes the effect of the two processes together is greater than the sum of the two acting individually [42].

The concept of dynamic durability related specifically to stones undergoing dynamic loading processes, and a more general dynamic concept of durability has not been widely taken into consideration. However, it is potentially a much more useful approach for stone conservation. The dynamic durability can be expressed simply as resilience, rather than resistance. Resilience has been defined as the ability to "tolerate disturbance without collapsing into a qualitatively different state controlled by a different set of processes" [43]. Behind the simple definition of resilience, there are some more advanced ideas of systems and interrelationships, with key aspects including the presence of multiple metastable regimes, the importance of episodic change, the existence of nested cycles with different scale properties, and the possibility of links across scales. Measurements of durability need to be based on resilience in the face of a wide range of deterioration processes, evaluated at different scales and under realistic environmental conditions. Assessments of how durability of stone evolves during exposure in monumental buildings are particularly needed and will involve combining laboratory and field exposure testing with non destructive monitoring of on site real cases. A key goal for stone decay scientists now is to provide more data on stone decay system inputs and outputs. In order to identify the presence of such non linear behaviour and to elucidate how likely it is to produce chaotic outcomes [39].

\section{MODELLING}

The key for effective assessment and management of risk is to be able to recognize which is the most plausible explanation under different circumstances and develop appropriate predictive strategies. One possible example is the CIDOC Conceptual Reference Model (CRM). A formal ontology intended to facilitate the integration, mediation and interchange of heterogeneous cultural heritage information for the exchange and integration of heterogeneous scientific documentation of museum collections. This model is the result of a long work made by the International Committee for Documentation (CIDOC) of the International Council of Museums (ICOM). The primary role of the CRM is to enable information exchange and integration between heterogeneous sources of cultural heritage information. It aims at providing the semantic definitions and clarifications needed to transform disparate, localized information sources into a coherent global resource. However, it does not define any data but foresees the characteristic relationships for its use to enable semantic interoperability [44].

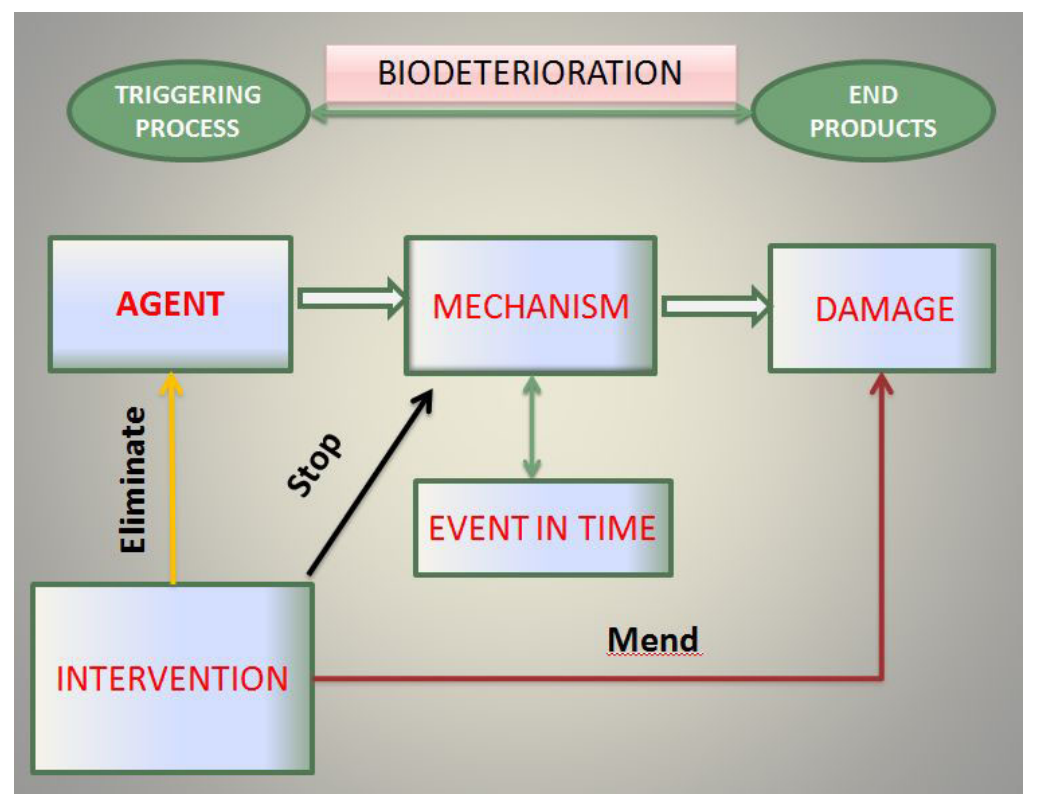

Fig. (3). Schematic representation of the biodeterioration ontological model.

A more appropriate model is present in the historical construction field [45]. This ontological model is described as an event, which might have a defined temporal reference, 'induces' a mechanism, carried out by an agent. The 
damaging mechanism results in a tangible damage observable on the substrate called manifestation of damage, which includes both material and component types of damage. Intervention is modeled as an action (or set of actions) aimed at repairing the manifestation of damage, stopping the damaging mechanism, eliminating the agent and preventing the event from occurring (see Fig. 3):

- what it is - (its essence)

- how it is - (its qualitativeness)

- how much it is - (its quantitativeness)

- where it is - (its relatedness to other beings).

Each class presents an internal organization of terminology derived from well established technical literature and can be further integrated or extended directly by user's input. Data management systems, in-situ documentation with portable diagnostic devices, as well as the correct diagnosis of causes of damages, allow feasible interventions [46].

\section{CONSIDERATION AND PERSPECTIVES}

Although, it is well established that microorganisms can cause serious damage to stone monuments, knowledge of the precise mechanisms of decay, is still fragmentary and not enclosed in more general models. The development of new identification methods provides us with a broader understanding of the diversity of organisms present on outdoor monuments and may expand our knowledge of new types of microbial metabolism occurring in these habitats. However, very little work has been carried out in studying the effective deteriorative activity of the old or newly identified organisms. A proteomic approach would not only clarify on the potential activity of microorganisms but would also help designing new strategies for isolating and culturing new organisms. Even microorganisms that have long been known to dwell on stone monuments have only rarely been appropriately examined for their effective contribution to stone decay in vivo. A description of criteria for determining that the decay of the stone is due to microbial action is rare in the literature. Similarly, very few studies aim to quantify biodeterioration processes. In fact, there have been no attempts to define the degree of biodeterioration of an artefact and at what stage antimicrobial and preventive actions should be initiated [22]. The concept of stone durability introduces the need to understand the complex interactions not only among stone, microorganisms and the surrounding environment, but even of chemical and physical processes. In order to achieve this aim, it is necessary to use and develop portable diagnostic devices which can quantify the ratio force/resistance of a single action. The identification of suitable parameters and the standardization of methods for their detection, assessment, and quantification is necessary to complete the equation. Interdisciplinary research projects between conservators and scientists, such as microbiologists, geologists, chemists and physicists, are needed in order to exchange and integrate heterogeneous scientific data of different research groups. Thinking of durability in terms of resilience rather than resistance may help to develop a more refined concept of durability, which can link different types and scales of deterioration, both in present and past. Furthermore, it provides a more realistic picture of the recursive relationship between environmental conditions (forces) and durability [35].

A key goal for monumental stone decay scientists, in collaboration with a mathematician expert of the complexity and an interactive database software developer, is now to provide more reliable data on inputs and outputs in stone decay system. This in order to identify and quantify such nonlinear behaviour and to elucidate how likely it is to produce (chaotic outcomes) intelligent probabilistic solutions for a suitable maintenance of our Monumental Heritage.

The data for the equation forces/resistance of each process should be obtained from peculiar science domains represented by a characterising indicator (Fig. 4). If we will be able to complete and realize all the domains involved in the specific process, with the suggested indicators and related parameters, device and protocols (Table 1), then we could build a new relational database MDDM (Management of Dynamic Durability Model). The attribution of a numeric value to the indicators, weighing and ranking the related parameters, will let us use it as a practical tool. As a signal of change (or stability), to evaluate and follow one of the dynamics "state of conservation of a monumental stone", while the MDDM should give, by their integration, suitable scheduled maintenance indications for the whole object (Fig. 5). 


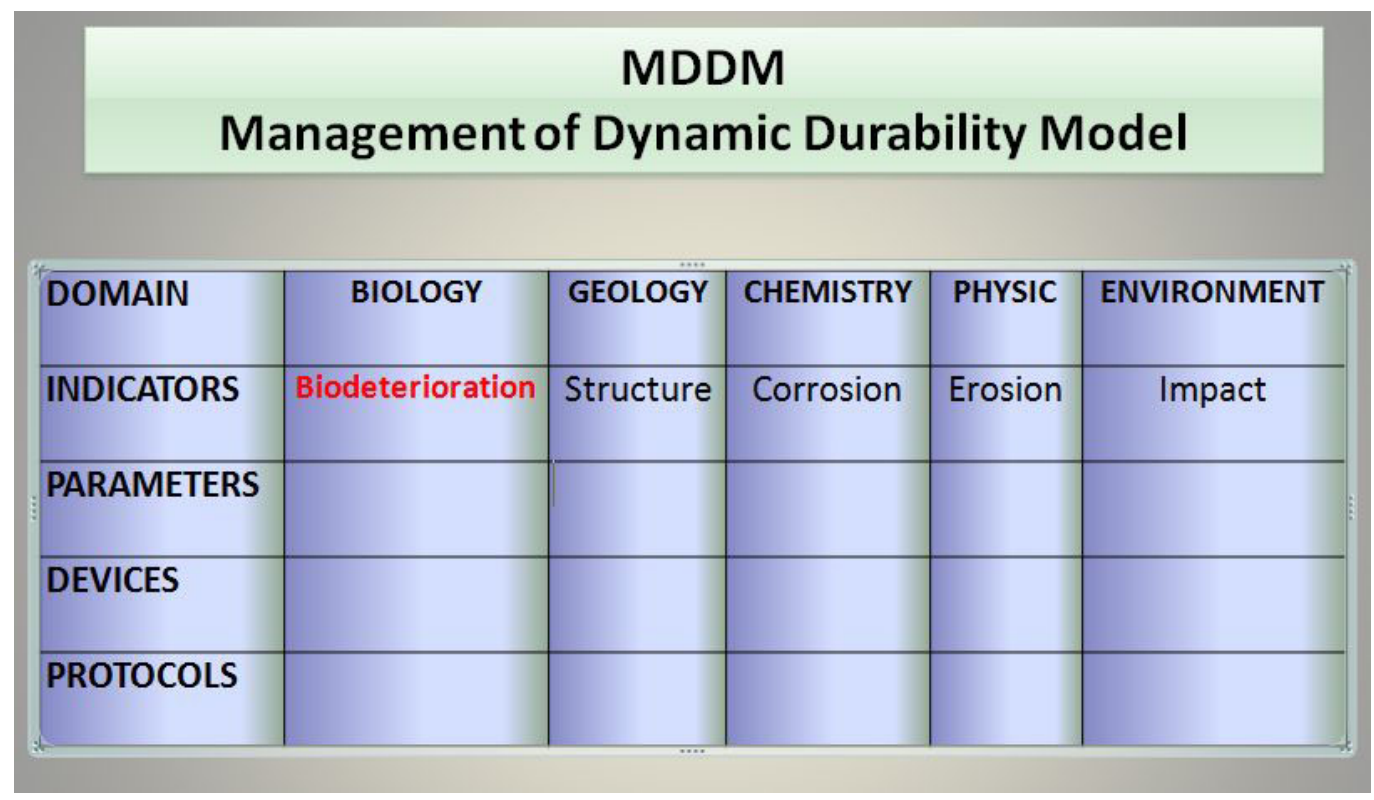

Fig. (4). Conceptual model of an interactive database MDDM (Management of Dynamic Durability Model).

Table 1. Specification of the domain biology.

\begin{tabular}{|c|c|}
\hline DOMAIN & BIOLOGY \\
\hline INDICATOR & BIODETERIORATION \\
\hline PARAMETER & $\begin{array}{l}\text { 1. Total number of cultivable organisms (autotrophic, heterotrophic, chemio-synthetic) } \\
\text { 2. Morphological and functional identification (number of genus - species) } \\
\text { 3. Molecular Identification (taxonomic categories) } \\
\text { 4. Fatty acids } \\
\text { 5. N/C Report } \\
\text { 6. Micro fauna and weeds (type and specification) } \\
\text { 7. Air contamination in the area } \\
\text { 8. Substrate Type }\end{array}$ \\
\hline INSTRUMENT & $\begin{array}{l}\text { 1. Techniques of Environmental Microbiology } \\
\text { 2. Optical microscopy SEM and CLSM, Biolog, API } \\
\text { 3. DGGE, real-Time PCR, FISH } \\
\text { 4. Gas Chromatograph } \\
\text { 5. Luminometer } \\
\text { 6. Elemental Analysis } \\
\text { 7. Sampling and direct observation (MO) } \\
\text { 8. Aerobiology } \\
\text { 9. XRD - XRF, Thin section } \\
\end{array}$ \\
\hline PROTOCOL & $\begin{array}{l}\text { 1. Sample type (tool, quantity, transport), Treatment type (suspension-dilution), Type of medium (total } \\
\text { microflora, actinomycetes, fungi, algae, protozoa, nitrogen cycle, carbon, sulfur), Type of Inoculation, } \\
\text { incubation and counts (CFU / MPN) } \\
\text { 2. Macroscopic and microscopic observation of isolated Physiological and Biochemical test } \\
\text { 3. Extraction and cloning of DNA, with PCR Real Time, FISH, T-RFLP } \\
\text { 4. DGGE analysis } \\
\text { 5. Extraction and determination of the ATP } \\
\text { 6. Chemical analysis for nitrogen and organic carbon (TOC) } \\
\text { 7. Type of sampling classification and counting } \\
\text { 8. Device and methods used } \\
\text { 9. Composition and structure of the substrate (mineralogical and petro graphic analyses) }\end{array}$ \\
\hline
\end{tabular}




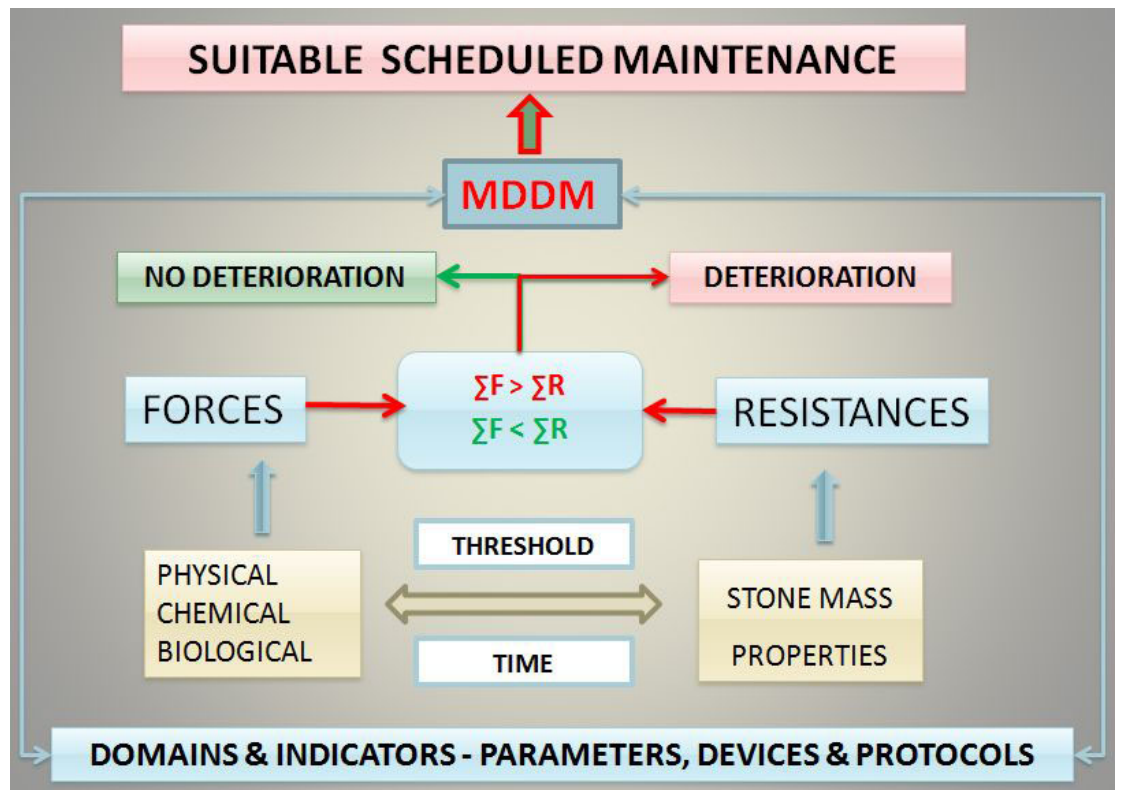

Fig. (5). Use of the MDDM for define sustainable scheduled maintenance interventions.

In conclusion, I would outline that every "intelligent data base" has a big limitation that the intelligence is that one of who built the system, even considering chaotic outcomes.

\section{CONFLICT OF INTEREST}

The author confirms that this article content has no conflict of interest.

\section{ACKNOWLEDGEMENTS}

Declared none.

\section{REFERENCES}

[1] Mihajlovski, A.; Seyer, D.; Benamara, H.; Bousta, F.; Di Martino, P. An overview of techniques for the characterization and quantification of microbial colonization on stone monuments. Ann. Microbiol., 2015, 65(3), 1243-1255. [http://dx.doi.org/10.1007/s13213-014-0956-2]

[2] Dakal, T.C.; Arora, P.K. Evaluation of potential of molecular and physical techniques in studying biodeterioration. Rev. Environ. Sci. Biotechnol., 2012, 11(1), 71-104.

[http://dx.doi.org/10.1007/s11157-012-9264-0]

[3] Polo, A.; Gulotta, D.; Santo, N. Importance of subaerial biofilms and airborne microflora in the deterioration of stonework: a molecular study. Biofouling, 2012, 28(10), 1093-1106.

[http://dx.doi.org/10.1080/08927014.2012.729580]

[4] Rakotonirainy, M.S.; Dubar, P. Application of bioluminescence ATP measurement for evaluation of fungal viability of foxing spots on old documents. Luminescence, 2013, 28, 308-312. [http://dx.doi.org/10.1002/bio.2382]

[5] Tiano, P.; Tomaselli, L.; Orlando, C. The ATP-Bioluminescence method for a rapid evaluation of the microbial activity in the stone materials of monuments. J. Biolumin. Chemilumin., 1989, 3, 213-216. [http://dx.doi.org/10.1002/bio.1170030409]

[6] Canhotoa, O.; Pinzari, F.; Fanelli, C.; Magan, N. Application of electronic nose technology for the detection of fungal contamination in library paper. Int. Biodeterior. Biodegradredation, 2004, 54, 303-309. [http://dx.doi.org/10.1016/j.ibiod.2004.04.001]

[7] Cuzman, O.; Tiano, P.; Ventura, S. New Control Methods Against Biofilms' Formation on the Monumental Stones In: Proceedings of 11th International Congress on Deterioration and Conservation of Stone; Torun, 2008; vol. 2, pp. 837-46.

[8] Roldán, M.; Hernández-Mariné, M. Exploring the secrets of the three dimensional architecture of phototrophic biofilms in caves. Int. J. Spel., 2009, 38(1), 41-53. [http://dx.doi.org/10.5038/1827-806X.38.1.5]

[9] Raimondi, V.; Cecchia, G.; Lognoli, D. Fluorescence lidar technique for the remote sensing of photoautotrophic biodeteriogens in the outdoor 
cultural heritage: A decade of in situ experiments. Int. Biodeterior. Biodegradredation, 2009, 63(7), 823-835. [http://dx.doi.org/10.1016/j.ibiod.2009.03.006]

[10] Osticioli, I.; Mascalchi, M.; Pinna, D.; Siano, S. Potential of Chlorophyll Fluorescence Imaging for Assessing Bio-Viability Changes of Biodeteriogen Growths on Stone Monuments 2013 In: Proceedings of SPIE 8790, Optics for Arts, Architecture, and Archaeology IV, 879003; , 2013.

[http://dx.doi.org/10.1117/12.2020563]

[11] Tiano, P.; Bianchi, R.; Gargani, G.; Vannucci, S. Research on the presence of sulphur cycle bacteria in the stone of some historical buildings in Florence. J. Plant Soil, 1975, 43, 211-217. [http://dx.doi.org/10.1007/BF01928487]

[12] Glamoclija, M.; Fogel, M.L.; Steele, A.; Kish, A. Microbial nitrogen and sulfur cycles at the gypsum dunes of white sands national monument, New Mexico. Geomicrobiol. J., 2012, 29(8), 733-751. [http://dx.doi.org/10.1080/01490451.2011.608111]

[13] Marvasi, M.; Donnarumma, F.; Frandi, A. Black microcolonial fungi as deteriogens of two famous marble statues in Florence, Italy. Int. Biodeterior. Biodegradredation, 2012, 68, 36-44. [http://dx.doi.org/10.1016/j.ibiod.2011.10.011]

[14] Cuzman, O.A.; Ventura, S.; Sili, C. Biodiversity of phototrophic biofilms dwelling on monumental fountains. Microb. Ecol., 2010, 60(1), 81-95. [http://dx.doi.org/10.1007/s00248-010-9672-z]

[15] Tiano, P; Tomaselli, L. Un caso di biodeteriorazione del Marmo. Notizie GOR., 1989, 6, 12-18.

[16] Zanardini, E.; Andreoni, V.; Borin, S. Lead-resistant microorganisms from red stains of marble of the Certosa of Pavia, Italy and use of nucleic acid based techniques for their detection. Int. Biodeterior. Biodegradredation, 1997, 40(2-4), 171-182. [http://dx.doi.org/10.1016/S0964-8305(97)00057-7]

[17] Piervittori, R.; Salvadori, O.; Isocrono, D. Literature on lichens and biodeterioration of stonework. J. Lichenologist, 2004, $36,145-157$. [http://dx.doi.org/10.1017/S0024282904014136]

[18] Pinna, D. Biofilms and lichens on stone monuments: do they damage or protect? Front. Microbiol., $2014,5,133$. [http://dx.doi.org/10.3389/fmicb.2014.00133]

[19] Ranalli, G.; Zanardini, E.; Sorlini, C. Biodeterioration Including Cultural Heritage. Encyclopedia of Microbiology; Schaechter, M., Ed.; Elsevier: Oxford, 2009, pp. 191-205.

[20] Dakal, T.C.; Cameotra, S.S. Microbially induced deterioration of architectural heritages: routes and mechanisms involved. Environ. Sci. Eur., 2012, 24,36 .

[http://dx.doi.org/10.1186/2190-4715-24-36]

[21] Warscheid, T.; Braams, J. Biodeterioration of stone: A review. Int. Biodeterior. Biodegradation, 2000, 46, $343-368$. [http://dx.doi.org/10.1016/S0964-8305(00)00109-8]

[22] Scheerer, S.; Ortega-Morales, O.; Gaylarde, C. Microbial deterioration of stone monuments-an updated overview. Adv. Appl. Microbiol., 2009, 66(5), 97-139.

[http://dx.doi.org/10.1016/S0065-2164(08)00805-8]

[23] De los Ríos, A; Pérez-Ortega, S; Wierzchos, J; Ascaso, C Differential effects of biocide treatments on saxicolous communities: Case study of the Segovia cathedral cloister (Spain). Int. Biodeterior. Biodegradredation, 2012, 67, 64-72.

[24] Webster, R.G.; Andrew, C.A.; Baxter, S. Stone cleaning in Scotland - Research Report to Historic Scotland and Scottish Enterprise by Masonry Conservation Research Group; Gilcomston Litho: Aberdeen, 1992.

[25] May, E. Microbes on building stone-For good or ill? Culture (Que.), 2003, 24, 5-8.

[26] Caneva, G.; Salvadori, O.; Ricci, S.; Ceschin, S. Biological Analysis for the Conservation of the Hieroglyphic Stairway of Copan (Honduras). "LABS5. Biodegradation and Biodeterioration in Latin America; Ortega-Morales, B.O.; Gaylarde, C.C.; Narvaez-Zapata, J.A.; Gaylarde, P.M., Eds.; Universidad de Campeche, Mexico, 2005, pp. 55-58.

[27] Leavengood, P.; Twilley, J.; Asmus, J.F. Lichen removal from Chinese spirit path figures of marble. J. Cult. Herit., 2000, S171-S174.

[28] Olmi, R.; Bini, M.; Ignesti, A. Investigation of the Microwave Heating Method for the Control of Biodeteriogens on Cultural Heritage Assets In: Proceedings of Art11 - $10^{\text {th }}$ International Conference on nondestructive investigations and microanalysis for diagnostic and conservation; Firenze: Italy, 2002; p. 23.

[29] Osticioli, I.; Mascalchi, M.; Pinna, D.; Siano, S. Removal of Verrucaria nigrescens from stone artifacts using Nd: YAG lasers: comparison among different pulse durations and wavelengths Appl. Phys. (Berl.), in press

[30] Young, M.E.; Alakomi, H.L.; Fortune, I. Development of a biocidal treatment regime to inhibit biological growths on cultural heritage. Biodam. Environ. Geol., 2008, 56(6), 631-664. [http://dx.doi.org/10.1007/s00254-008-1455-1]

[31] Salvadori, O.; Charola, A.E. Methods to Prevent Biocolonization and Recolonization: An Overview of Current Research for Architectural and Archaeological Heritage; Smithsonian Institution Scholarly Press, 2011, pp. 37-50. 
[32] Pinna, D.; Salvadori, B.; Galeotti, M. Monitoring the performance of innovative and traditional biocides mixed with consolidants and waterrepellents for the prevention of biological growth on stone. Sci. Total Environ., 2012, 423, 132-141. [http://dx.doi.org/10.1016/j.scitotenv.2012.02.012]

[33] Warscheid, T.; Leisen, H. Microbiological Studies on Stone Deterioration and Development of Conservation Measures at Angkor Wat, In: Proceedings of the Workshop Biocolonizatio, of Stone: Control and Preventive Methods. Smithsonian Institution: Scholarly Press. 2011, pp. $1-18$.

[34] Viles, H.A.; Camuffo, D.; Fitz, S. What is the state of our knowledge of the mechanisms of deterioration and how good are our estimates of rates of deterioration. In: Saving our Architectural Heritage - The conservation of Historic Stone Structures; Baer, N.S.; Snethlage, R., Eds.; Wiley: Chichester, 1997; pp. 95-112.

[35] Krumbein, W.E.; Briblecombe, P.; Cosgrove, D.E.; Staniforth, S. Durability and Change: The Science; Responsibility, and Cost of Sustaining Cultural Heritage, 1994.

[36] Naylor, L.A.; Coombes, M.A.; Viles, H.A. Reconceptualising the role of organisms in the erosion of rock coasts: A new model. Geomicrobiol. J., 2012, 157-158, 17-30.

[37] Viles, H.A. Durability and conservation of stone: coping with complexity. Q. J. Eng. Geol. Hydrogeol., 2013, 46, 367-375. [http://dx.doi.org/10.1144/qjegh2012-053]

[38] Cassar, J; Vella, AJ Methodology to identify badly weathering limestone using geochemistry. Case study on the Lower Globigerina Limestone of the Maltese Islands. Q. J. Eng. Geol. Hydrogeol., 2003, 36, 85-96.

[39] Viles, H.A. Can stone decay be chaotic? Spec. Pap. Geol. Soc. Am., 2005, 390, 11-16.

[40] Phillips, J.D. Sources of non-linearity and complexity in geomorphic systems. Prog. Phys. Geogr., 2003, $27,1-23$. [http://dx.doi.org/10.1191/0309133303pp340ra]

[41] Kumar, R.; Kumar, A.V. Biodeterioration of stone in tropical environments: An overview: Research in Conservation Series, Los Angeles. Getty Conserv. Inst., 1999, 1, 85.

[42] Papida, S.; Murphy, W.; May, E. Enhancement of physical weathering of building stones by microbial populations. Int. Biodeterior. Biodegradredation, 2000, 46, 305-317. [http://dx.doi.org/10.1016/S0964-8305(00)00102-5]

[43] Dearing, J.A. Landscape change and resilience theory: A palaeo environmental assessment from Yunnan, SW China. Holocene, 2008, 18, $117-127$. [http://dx.doi.org/10.1177/0959683607085601]

[44] Definition of the CIDOC Conceptual Reference Model-Produced by the ICOM/CIDOC Documentation Standards Group, continued by the CIDOC CRM Special Interest Group, Version 5.0.2, 2010. [January 2010].

[45] Cacciotti, R.; Blăsko, M.; Valach, J. A diagnostic ontological model for damages to historical constructions. J. Cult. Herit., 2014, 6(1), 40-48.

[46] Illustrated glossary on stone deterioration patterns Raccomandazione UNI-EN 1182: 2006 (ex UNI Normal 1/88).: ICOMOS, France, 2010.

Received: January 15, 2015

Revised: May 25, 2015

Accepted: July 31,2015

(C) Piero Tiano; Licensee Bentham Open.

This is an open access article licensed under the terms of the Creative Commons Attribution-Non-Commercial 4.0 International Public License (CC BY-NC 4.0) (https://creativecommons.org/licenses/by-nc/4.0/legalcode), which permits unrestricted, non-commercial use, distribution and reproduction in any medium, provided the work is properly cited. 